\title{
Effect of nano-SiO 2 particles and curing time on development of fiber-matrix bond properties and microstructure of ultra-high strength
}

\section{concrete}

\author{
Zemei $\mathrm{Wu}^{\text {a, b }}$, Kamal Henri Khayat ${ }^{\text {a, b, * }}$, Caijun Shi ${ }^{\text {a,* }}$ \\ ${ }^{a}$ College of Civil Engineering, Hunan University, Changsha 410082, Hunan, PR China \\ ${ }^{b}$ Department of Civil, Architectural and Environmental Engineering, Missouri University of Science and Technology, Rolla \\ 65409, Missouri, USA
}

\begin{abstract}
Bond properties between fibers and cementitious matrix have significant effect on the mechanical behavior of composite materials. In this study, the development of steel fiber-matrix interfacial bond properties in ultra-high strength concrete (UHSC) proportioned with nano- $\mathrm{SiO}_{2}$ varying between 0 to $2 \%$, by mass of cementitious materials, was investigated. A quadratic model relating either bond strength or pullout energy to curing time and nano- $\mathrm{SiO}_{2}$ content was proposed by using the response surface methodology. Mercury intrusion porosimetry (MIP) and backscatter scanning electron microscopy (BSEM) were used to characterize the microstructure of the matrix and the fiber-matrix interface, respectively. Micro-hardness around the embedded fiber and hydration products of the matrix were evaluated as well. Test results indicated that the optimal nano- $\mathrm{SiO}_{2}$ dosage was $1 \%$ in terms of the bond properties and the microstructure. The proposed quadratic model efficiently predicted the bond strength and pullout energy with consideration of curing time and nano- $\mathrm{SiO}_{2}$ content. The improvement in bond properties associated with nano-silica was correlated with denser matrix and/or interface and stronger bond and greater strength of hydration products based on microstructural analysis.
\end{abstract}

Keywords: Bond strength; Microstructural analysis; Nano-SiO 2 ; Pullout energy; Quadratic model; Steel

\footnotetext{
$1 *$ Corresponding author.

E-mail address: zemianmian@gmail.com (Z. Wu); khayatk@mst.edu (K.H. Khayat); cshi@ hnu.edu.cn (C. Shi)
} 
fiber; UHSC

\section{Introduction}

Ultra-high performance concrete (UHPC) is an advanced composite material typically made with very low water-to-binder ratio of $0.20 \pm 0.02$ and contains high content of binder, high efficiency superplasticizer, and high strength fibers [1]. As an intrinsically heterogeneous material, its mechanical properties are governed by the quality of the matrix, the characteristic of the fiber, and the quality of the interfacial transition zone (ITZ) between the fiber or aggregate and the matrix [2-4]. The bond properties of fiber-matrix interface play a predominant role in the mechanical properties of composite materials because of stress transferring at this interface, which can make an intrinsically brittle material into a ductile one [5, 6]. The microstructure of UHPC is denser and more homogenous than that of ordinary concrete [7, 8]. However, as the fiber-matrix interface bridging different phases with various stiffnesses, it is a special component and still the most important yet least understood part in UHPC. Therefore, optimization of the properties at the fiber-matrix interface is necessary for improving the overall mechanical behavior of composite materials.

With the advance and development of nanotechnology, the efficiency of using nano- $\mathrm{SiO}_{2}$ in cement-based materials has been investigated. These include the effect on microstructure [9, 10], heat of hydration [10, 11], workability and rheological properties [12-15], mechanical properties [9, 16], dimensional stability [17], and durability [18, 19]. Because of its extremely small size and highly pozzolanic activity, it can act as nuclei or filler in cement paste to accelerate the heat of hydration [11], densify the microstructure $[9,10]$, and hence enhance the homogeneity and improve the early-age mechanical properties and durability $[16,17]$. So far, no information focuses on the contribution of nano-particles on the interfacial bond properties between fibers and ultra-high strength concrete (UHSC).

This study aims at investigating the influence of different nano- $\mathrm{SiO}_{2}$ contents, varying from 0 to $2 \%$, by 
mass of cementitious material, on the fiber-matrix bond and microstructure of UHSC. A simple and effective doubled-sided pullout testing was conducted to evaluate the interfacial bond properties, which include pullout load-slip relationship, bond strength, and pullout energy. Mercury intrusion porosimetry (MIP), backscatter scanning electron microscopy (BSEM), micro-hardness measurement, and X-ray diffraction (XRD) analysis were employed to evaluate the microstructural features associated with the matrix and/or interface. It seeks to develop a statistical model to evaluate the couple effect of curing time and nano-SiO${ }_{2}$ content on bond properties and clarify the reinforcing mechanism of fiber-matrix bond associated with nano- $\mathrm{SiO}_{2}$.

\section{Materials and experiment program}

\subsection{Materials}

A type P.I 42.5 portland cement conforming to Chinese Standards was used. Powder silica fume (SF) with particle sizes in the range of 0.02 to $0.28 \mu \mathrm{m}$ and $\mathrm{SiO}_{2}$ content of $93.9 \%$ was used. Powder nano- $\mathrm{SiO}_{2}$ with an average particle size of $20 \mathrm{~nm}$ and $\mathrm{SiO}_{2}$ content of $99.8 \%$ was employed. The main chemical composition and physical properties of the cement, silica fume (SF), and nano- $\mathrm{SiO}_{2}$ are summarized in Table 1.

Natural river sand with a maximum particle size of $2.36 \mathrm{~mm}$ and a fineness modulus of 3.0 was used. A polycarboxylate-based superplasticizer (SP) with good fluidity retention and solid content of approximately $20 \%$ was used. Straight brass-coated steel fibers with a diameter of $0.2 \mathrm{~mm}$ and a length of $13 \mathrm{~mm}$ were used. 
Table 1 Chemical composition and physical properties of cementitious materials

\begin{tabular}{|c|c|c|c|c|}
\hline Materials & & Cement & Silica fume & $\mathrm{Nano}_{-\mathrm{SiO}_{2}}$ \\
\hline $\mathrm{SiO}_{2}(\%)$ & & 21.18 & 93.9 & 99.8 \\
\hline $\mathrm{Al}_{2} \mathrm{O}_{3}(\%)$ & & 4.73 & - & - \\
\hline $\mathrm{Fe}_{2} \mathrm{O}_{3}(\%)$ & & 3.41 & 0.59 & - \\
\hline $\mathrm{SO}_{3}(\%)$ & & 2.83 & - & - \\
\hline $\mathrm{CaO}(\%)$ & & 62.49 & 1.85 & - \\
\hline $\mathrm{MgO}(\%)$ & & 2.53 & 0.27 & - \\
\hline $\mathrm{Na}_{2} \mathrm{O}(\%)$ & & - & 0.17 & - \\
\hline $\mathrm{K}_{2} \mathrm{O}(\%)$ & & - & 0.86 & - \\
\hline Loss on ignition (\%) & & 1.20 & 0.30 & - \\
\hline Blain surface area $\left(\mathrm{m}^{2} / \mathrm{kg}\right)$ & & 350 & - & - \\
\hline BET surface area $\left(\mathrm{m}^{2} / \mathrm{kg}\right)$ & & - & 18,500 & 160,000 \\
\hline Specific gravity $\left(\mathrm{kg} / \mathrm{m}^{3}\right)$ & & 3,140 & 2,200 & - \\
\hline Average particle size (nm) & & 36,700 & 150 & 20 \\
\hline \multirow[t]{2}{*}{ Setting time $(\min )$} & Initial & 172 & - & - \\
\hline & Final & 222 & - & - \\
\hline Compressive strength (MPa) & $3 \mathrm{~d}$ & 28.3 & - & - \\
\hline Flexural strength (MPa) & $3 \mathrm{~d}$ & 5.6 & - & - \\
\hline
\end{tabular}

2.2. UHSC mixture proportioning and sample preparation

Five mixtures incorporating $0,0.5 \%, 1.0 \%, 1.5 \%$, and $2.0 \%$ of nano- $\mathrm{SiO}_{2}$, by mass of cementitious material, were prepared. These were designated as NS0, NS0.5, NS1.0, NS1.5, and NS2.0, respectively. Table 2 presents the mixture proportioning of these materials. According to the previous study [20], a water-to-cementitious materials ratio $(\mathrm{W} / \mathrm{CM})$ of 0.18 was adopted to ensure high mechanical properties. The dosage of SP was set at $2 \%$, by mass of cementitious materials. This dosage corresponds to a well-dispersed system for the reference mixture made without any nano-material [10].

The dry ingredients were mixed at a low speed for $3 \mathrm{~min}$. Water and SP were then slowly introduced and the materials were mixed for approximately $6 \mathrm{~min}$ at a low speed and for $1 \mathrm{~min}$ at a high speed. The mixture was then sampled for workability testing. Cubic samples with size of $40 \times 40 \times 40 \mathrm{~mm}$ for compressive strength testing and dog-bone samples for pullout testing were casted and consolidated for approximately $20 \mathrm{~s}$ by using a vibrating table. The samples were demolded after $24 \mathrm{~h}$ standard curing and then cured in lime-saturated water until 3, 7, 28, and $91 \mathrm{~d}$. 
Table 2 Mixture proportioning and flowability of UHSC

\begin{tabular}{|c|c|c|c|c|c|c|c|c|}
\hline \multirow{2}{*}{ No. } & \multirow{2}{*}{$\mathrm{W} / \mathrm{CM}$} & \multicolumn{6}{|c|}{ Mass of ingredient $\left(\mathrm{kg} / \mathrm{m}^{3}\right)$} & \multirow{2}{*}{$\begin{array}{l}\text { Mini slump } \\
\text { flow (mm) }\end{array}$} \\
\hline & & Water & Sand & Cement & SF & Nano-SiO ${ }_{2}$ & Superplasticizer & \\
\hline NS0 & 0.18 & 177 & 1079 & 863 & 216 & 0 & 21.6 & 210 \\
\hline NS0.5 & 0.18 & 177 & 1079 & 858 & 216 & 5.4 & 21.6 & 210 \\
\hline NS1.0 & 0.18 & 177 & 1079 & 852 & 216 & 10.8 & 21.6 & 190 \\
\hline NS1.5 & 0.18 & 177 & 1079 & 847 & 216 & 16.2 & 21.6 & 180 \\
\hline $\mathrm{NS} 2.0$ & 0.18 & 177 & 1079 & 842 & 216 & 21.6 & 21.6 & 155 \\
\hline
\end{tabular}

\subsection{Experimental methods}

\subsubsection{Fiber pullout testing}

According to the methods of applying force and fiber embedment, pullout testing can be divided into a single-sided and a double-sided pullout testing [21]. In view of the fibers are fully embedded in a real composite material, the double-sided pullout testing approach was adopted in this research. Dog-bone shaped specimens were used to measure the pullout behavior of four embedded fibers within the UHSC matrix according to the Chinese Standards CECS13-2009 [22]. The sample was divided into a pullout half and a fixed half from the center by using a plastic clip with four fibers that are firmly fixed to the clip. In order to ensure that the fibers can be pulled out from the pullout section, the embedded lengths of the fibers in the two section were different. Detailed information on fiber fixing and sample casting can be found in Ref. [21]. According to the standard [22], the embedded length of fiber $\left(l_{e m}\right)$ at the pullout section should meet the following requirements:

$$
\begin{aligned}
& l_{\mathrm{em}} \leqslant 0.4 l_{f} \\
& l_{\mathrm{em}}>f_{t} d_{\mathrm{eq}} / f_{m}
\end{aligned}
$$

where $l_{\mathrm{em}}(\mathrm{mm})$ is the embedded fiber length at the pullout half; $l_{f}(\mathrm{~mm})$ is the total length of steel fiber; $f_{t}$ $(\mathrm{MPa})$ is the tensile strength of steel fiber; $d_{\mathrm{eq}}(\mathrm{mm})$ is the diameter of steel fiber; and $f_{\mathrm{m}}(\mathrm{MPa})$ is the compressive strength of UHSC matrix.

Through calculation, the fiber in length in the pullout section was set to $5 \mathrm{~mm}$ compared to $8 \mathrm{~mm}$ in the 
fixed section. An MTS testing machine with $20 \mathrm{k} \mathrm{N}$ load cell was used to conduct pullout testing under a loading rate of $1 \mathrm{~mm} / \mathrm{min}$. For each matrix, five specimens were tested. To ensure the reliability of results, only the results of those specimens with all the four fibers pulled out from the pullout half of the sample (short embedment length) were used. The bond strength can be calculated as follows:

$$
\tau_{\max }=\frac{P_{\max }}{n \pi d l}
$$

where $\tau_{\max }(\mathrm{MPa})$ is the bond strength of the embedded fibers based on the maximum pullout load; $P_{\max }(\mathrm{N})$ is the maximum pullout load; $d(\mathrm{~mm})$ is the diameter of a single fiber, $0.2 \mathrm{~mm} ; l(\mathrm{~mm})$ is the embedment length of the fiber in the pullout half of the dog-bone sample, $5 \mathrm{~mm} ; n$ is the number of fibers embedded in a dog-bone specimen, 4 .

\subsubsection{Pore structure measurement}

Matrix samples with size of 3.5 to $5.0 \mathrm{~mm}$ from the inside of the dog-bone samples at given age were taken to evaluate pore size distribution using mercury intrusion porosimetry (MIP). The samples were soaked in acetone to stop further hydration and then dried at $60^{\circ} \mathrm{C}$ in an oven for $24 \mathrm{~h}$ before examination. The MIP experiments were sequential carried out under low and high pressures of 0.2758 and $414 \mathrm{MPa}$, respectively. Glass tube with the mortar specimen and mercury was placed in low and high pressure analysis ports. Full-scan auto mode was selected with contact angle and surface tension of $140^{\circ}$ and $480 \mathrm{mN} / \mathrm{m}$, respectively. The intrusion mercury volume was recorded at each pressure point.

\subsubsection{BSEM observation}

Small samples measuring $15 \times 15 \times 15 \mathrm{~mm}$ with an embedded fiber at the fixed half of the dog-bone shaped sample were taken by cutting the dog-bone shaped specimens shortly after the pullout testing. They 
were soaked and dried as MIP samples did and then grinded and polished with high smooth surface quality. The polished samples were coated with gold and examined using a Hetachi S4700-SEM with the back-scattered detector. Images with a resolution of $2560 \times 1920$ were taken at 250 magnifications.

\subsubsection{Micro-hardness measurement}

Micro-indention is based on applying a static load for a known period of time and measuring the response in terms of the indentation size. In this study, a $498 \mathrm{mN}$ load was applied on the same samples for BSEM testing for $10 \mathrm{~s}$. Measurement was performed within a distance of $240 \mu \mathrm{m}$ from the edge of embedded fiber. Four replicate indentations with constant distance of approximately $40 \mu \mathrm{m}$ to the previous indentation were performed, as shown in Fig. 1(a). During the indention process, areas with sand were avoided to ensure precise comparison of results from different matrices. A typical microscope images during testing is shown in Fig. 1(b). Means of four values of micro-hardness or Vickers hardness (HV) situated along a given distance from fiber edge was determined and reported.

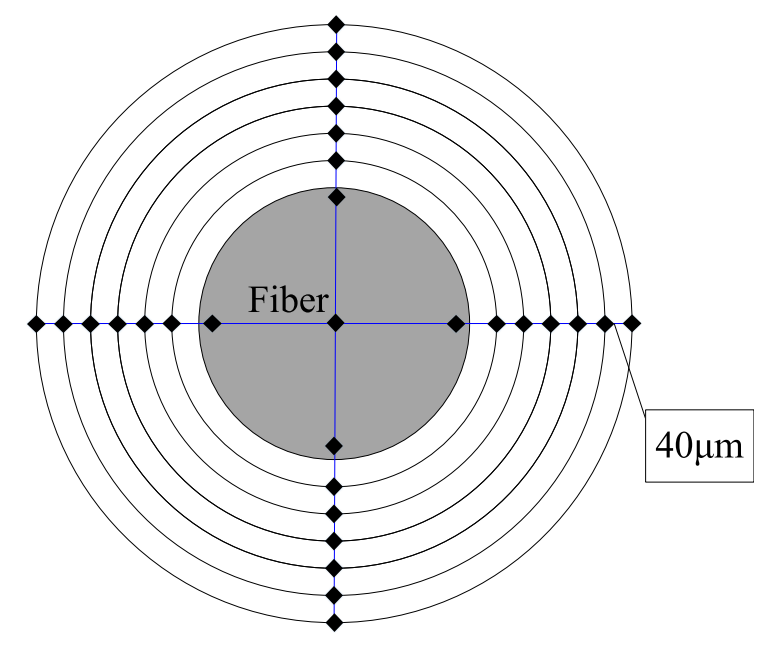

(a) Illustration of measurement

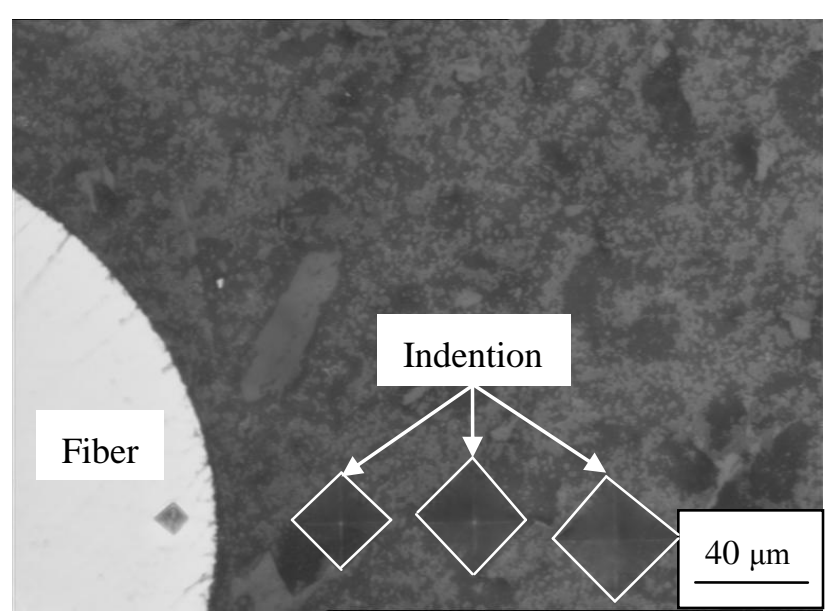

(b) Indention imàge

Fig. 1 Micro-hardness testing for UHSC matrix with an embedded fiber 


\subsubsection{XRD}

UHSC samples were taken from the dog-bone specimens after pullout testing for X-ray diffraction (XRD) analysis. The samples were soaked in acetone to stop cement hydration, then dried at $60^{\circ} \mathrm{C}$ for $24 \mathrm{~h}$ and ground into powder. $\mathrm{CuK} \alpha \mathrm{X}$-ray diffraction was used to characterize the crystalline phases of the sample. The experiments were carried out at $2 \theta$ value from $5^{\circ}$ to $65^{\circ}$ with a scan rate of $2 \% \mathrm{~min}$.

\section{Results and discussion}

\subsection{Effect of nano-SiO 2 on interfacial bond properties between fibers and UHSC matrix}

\subsubsection{Pullout load-slip relationship and bond strength}

Figure 2 shows the effect of nano-SiO 2 content on pullout load-slip curves of embedded fibers in UHSC at 3 and $91 \mathrm{~d}$. Generally, the pullout behavior can be divided into four distinct regions, including well bonded region $(\mathrm{OP})$, partially debonded region $(\mathrm{PQ})$, fully debonded region $(\mathrm{QR})$, and fiber pullout/slip region (RS), as illustrated in Fig. 3 [23, 24]. At the well bonded region, the pullout load increases linearly with slip at low slip values. The resistance in this stage is provided by adhesion or chemical bond with surrounding UHSC matrix [25]. When the peak load was achieved, the load began to decrease. However, the mixtures with nano- $\mathrm{SiO}_{2}$ did not show suddenly and dramatically drop of load with the increasing of slip from approximately 1 to $3 \mathrm{~mm}$. This can be due to high frictional coefficient and fiber surface pressure associated with higher matrix packing density from the surrounding mortar [26, 27]. In this range, fibers were gradually debonded and pulled out from the UHSC matrix with occurrence of micro-cracking at the ITZ. Once the fibers were fully debonded from the matrix (point R in Fig. 3), the pullout behavior is mainly governed by friction stress, which is a combined action of abrasion and compaction of cement and sand particles surrounding the fibers $[23,27]$. The friction shear stress decreased with the increase of slip due to the crumbling of cement matrix and decrease of roughness of the failure surface $[23,27]$. 


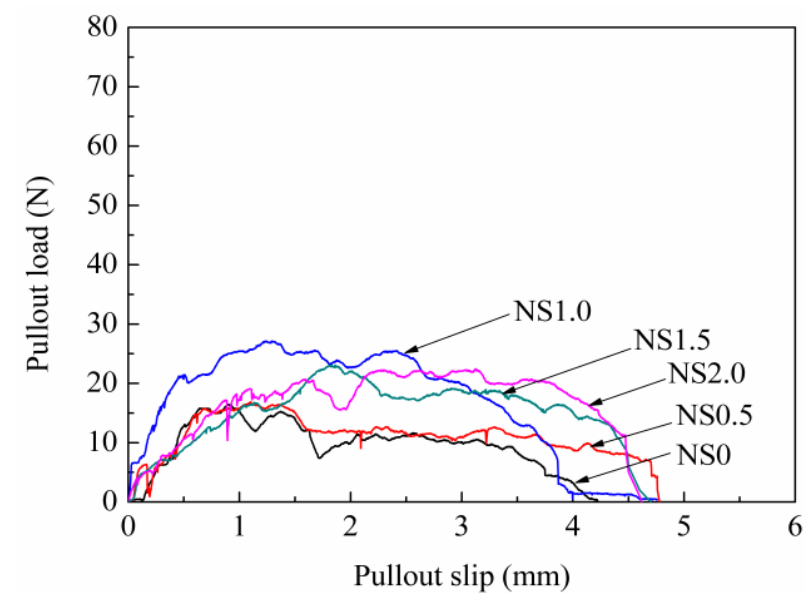

(a) $3 \mathrm{~d}$

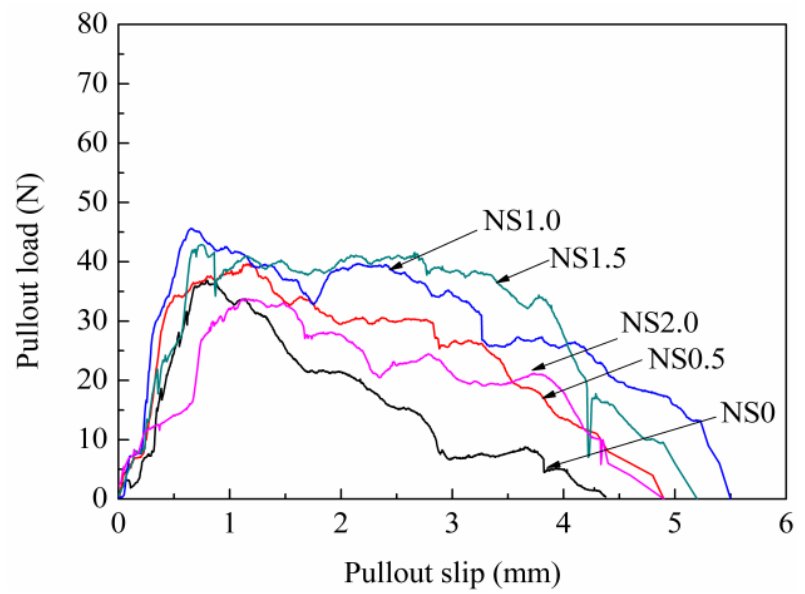

(b) $91 \mathrm{~d}$

Fig. 2 Pullout load-slip curves of embedded fibers in UHSC matrix with different nano-SiO 2 contents

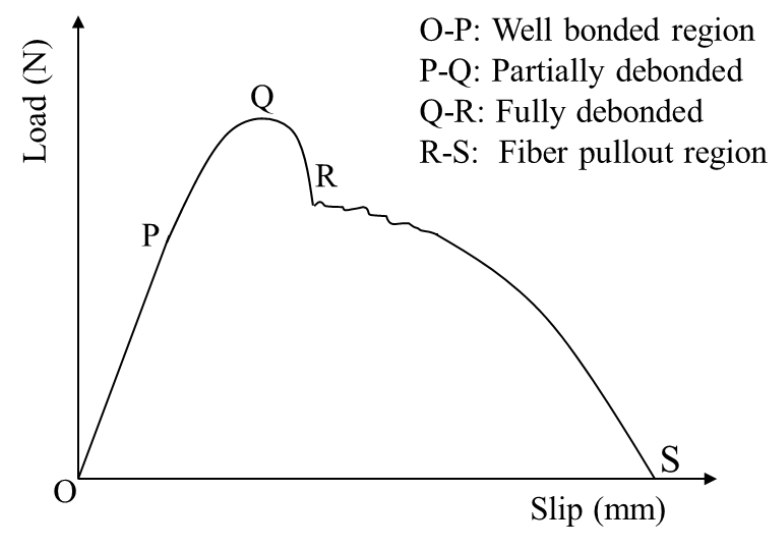

Fig. 3 Typical pullout load versus slip relationship (modified based on Ref. [28, 40])

The load at slip of $0.3 \mathrm{~mm}$, peak load, and initial frictional load are compared in Fig. 4 . The load at 0.3 mm slip was determined from the linear ascending part of the pullout load-slip curve. A steep drop of the load-deflection curve after reaching the peak load indicates the end of fully debonded area, as illustrated in Fig. $3[28,40]$. The residual pullout force after the steep drop was therefore used to characterize the initial frictional resistance $[28,40]$. As can be seen from Fig. 4, the load at slip of $0.3 \mathrm{~mm}$, peak load, and the initial frictional load increased gradually with the increase of nano- $\mathrm{SiO}_{2}$ content to $1.0 \%$ and decreased thereafter. The load at slip of $0.3 \mathrm{~mm}$, peak load, and initial frictional load of the NS1.0 matrix at $91 \mathrm{~d}$ were 27,46 , and $42 \mathrm{~N}$, respectively. Such values for the NS0 matrix were 8, 37, and $33 \mathrm{~N}$, respectively. Therefore, the incorporation of $1 \%$ nano- $\mathrm{SiO}_{2}$ significantly improved the chemical bond and friction stress to the 
surrounding cement matrix. This can be associated with the greater content of C-S-H gel of higher density at the fiber-matrix interface $[9,10,21]$. However, when high nano- $\mathrm{SiO}_{2}$ content was used, the improvement efficiency decreased because of entrapped pores due to agglomeration issues of the nano-particles. Such increase in porosity was discussed in Section 3.2.1.

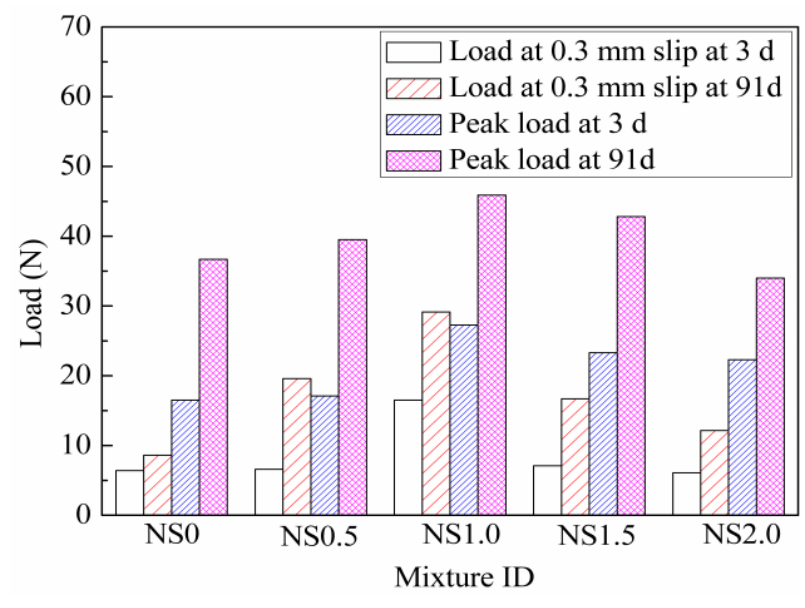

(a) Pullout load at $0.3 \mathrm{~mm}$ slip and peak load

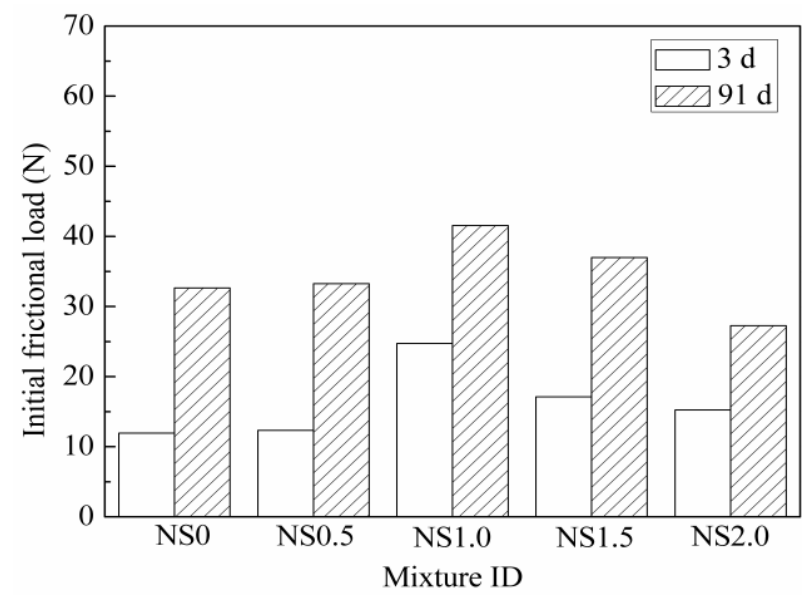

(b) Initial frictional load

Fig. 4 Effect of nano-SiO 2 content on pullout load and initial frictional load of fiber-matrix interface

Figure 5 illustrates the effect of nano- $\mathrm{SiO}_{2}$ content on bond strength of fiber-matrix interface and compressive strength of UHSC matrix. As can be seen from Fig. 5(a), the bond strength increased with the increase of nano- $\mathrm{SiO}_{2}$ content from 0 to approximately $1 \%$, but then decreased at a higher content. For the NS2.0 matrix, the bond strengths were reduced to comparable values as that of the NS0.5 matrix. Therefore, the optimal nano- $\mathrm{SiO}_{2}$ content for bond strength can be considered to be $1 \%$. The mini slump flow of UHSC incorporated with $1 \%$ nano- $\mathrm{SiO}_{2}$ was $190 \mathrm{~mm}$, as shown in Table 2 . This value dropped to $150 \mathrm{~mm}$ at $2 \%$ nano- $\mathrm{SiO}_{2}$. Agglomeration issues associated with excessive nano- $\mathrm{SiO}_{2}$ dosage can lead to some weak zones in the internal structure of concrete $[14,15]$.

As can be also seen from Fig. 5(a), bond strength increased considerable at early age up to 7 d, and increased slightly afterwards until the age of $91 \mathrm{~d}$. The bond strength of the NS1.0 mixture at $1 \mathrm{~d}$ was approximately $2 \mathrm{MPa}$, it increased to $3.5 \mathrm{MPa}$ at $7 \mathrm{~d}$ and to approximately $4 \mathrm{MPa}$ at $91 \mathrm{~d}$. Chan and Chu [29] 
investigated the fiber-matrix bond strength of reactive powder concrete at a W/CM ratio of 0.21 to 0.23 under 3-d high-temperature curing. The bond strength for nine fibers with an embedded fiber length of 10 mm was 5.5 MPa. Greater bond strength in that research was because of the change in $\mathrm{C}-\mathrm{S}-\mathrm{H}$ structure associated with higher temperature curing $[30,31]$. The bond strength in this research agrees well with the change in compressive strength of the UHSC matrix, as illustrated in Fig. 5(b). Generally, the higher the compressive strength of the matrix is, the greater the bond strength is $[21,32]$. Nano- $\mathrm{SiO}_{2}$ particles can increase the heat of hydration due to filler effect and pozzolanic activity [10], and hence densify the microstructure and improve early-age mechanical properties $[9,10,14]$.

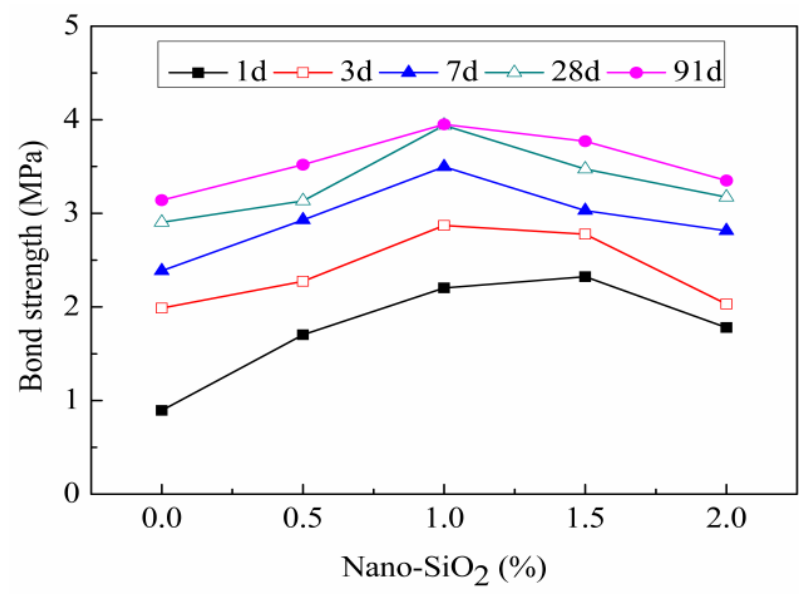

(a) Bond strength of fiber-matrix interface

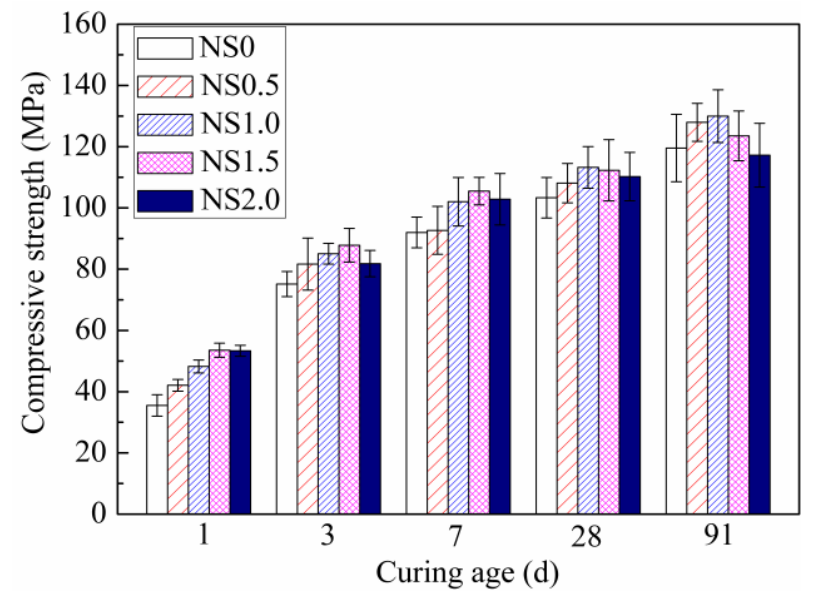

(b) Compressive strength of UHSC matrix [10]

Fig. 5 Effect of nano-SiO${ }_{2}$ content on bond strength of fiber-matrix interface and compressive strength of UHSC matrix

\subsubsection{Bond strength prediction}

Using the response surface methodology, bond strength at fiber-matrix interface of UHSC made with various nano- $\mathrm{SiO}_{2}$ contents under different curing ages can be predicted using the second order model, as expressed by Equation (4) [33]:

$$
Y=b_{0}+\sum_{i=1}^{k} b_{i} X_{i}+\sum_{i=1}^{k} b_{i} X_{i}^{2}+\sum_{i<j} \sum b_{i j} X_{i} X_{j}
$$

where $\mathrm{Y}$ is the predicted response; $\mathrm{X}_{\mathrm{i}}$ is the quantitative variable $(\mathrm{i}=1,2,3, \ldots) ; \mathrm{b}_{0}, \mathrm{~b}_{\mathrm{i}}$, and $\mathrm{b}_{\mathrm{ij}}$ are the least 
square estimates of the regression coefficients.

Table 3 summarizes the statistical analysis results for bond strength. Conducting the Student $\mathrm{t}$ test with a significant level of 0.05 , the model should allow those terms with a "Prob>|t|" value less than 0.05 , which is considered to be statistically significant. This was not the case for the $\left(\mathrm{Nano}-\mathrm{SiO}_{2} \text { content }-0.01\right)^{*}(\mathrm{Age}-$ 26) term, which can be considered to have little effect on bond strength. Therefore, the predicted bond strength $\left(\tau_{\max }\right)$ can be expressed as follows:

$$
\tau_{\max }=2.552+25.122 \mathrm{X}_{2}+0.037 \mathrm{X}_{1}+\left(\mathrm{X}_{2}-0.01\right)^{2}+\left(\mathrm{X}_{1}-26\right)^{2}
$$

where $\tau_{\max }(\mathrm{MPa})$ is the predicted bond strength; $\mathrm{X}_{1}(\mathrm{~d})$ is the curing age; $\mathrm{X}_{2}$ is the nano-SiO${ }_{2}$ content, by mass of cementitious materials.

Table 3 Analysis of variance (ANOVA) for bond strength

\begin{tabular}{|c|c|c|c|c|}
\hline Term & Estimate & Std Error & t Ratio & Prob $>|t|$ \\
\hline Intercept & 2.552398 & 0.155037 & 16.46 & $<0.0001 *$ \\
\hline Nano-SiO ${ }_{2}$ content & 25.121720 & 9.779383 & 2.57 & $0.0188 *$ \\
\hline Age & 0.037125 & 0.004976 & 7.46 & $<0.0001 *$ \\
\hline 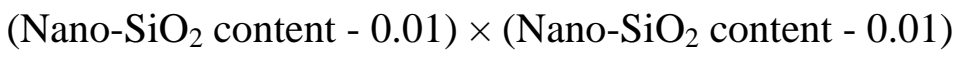 & -7644.726 & 1653.017 & -4.62 & $0.0002 *$ \\
\hline$($ Age -26$) \times($ Age -26$)$ & -0.000536 & 0.000109 & -4.93 & $<0.0001 *$ \\
\hline$\left(\right.$ Nano- $\mathrm{SiO}_{2}$ content -0.01$) \times($ Age -26$)$ & -0.221981 & 0.288529 & -0.77 & 0.4511 \\
\hline
\end{tabular}

Note: $*$ denotes statistically significant term

Equation (6) was derived by expanding Equation (5):

$$
\tau_{\max }=1.426+0.0651 \mathrm{X}_{1}+152.932 \mathrm{X}_{2}-0.0005 \mathrm{X}_{1}^{2}-7644.726 \mathrm{X}_{2}^{2}
$$

The contour map and actual by predicted plot for bond strength is shown in Fig. 6. As observed from Fig. 6(a), good bond strength over $3 \mathrm{MPa}$ was obtained for samples with nano-SiO${ }_{2}$ content in the range of $0.5 \%$ to $1.0 \%$ after approximately $8 \mathrm{~d}$. The actual bond strength was closely scattered around the line of equality with a correlation coefficient $\left(\mathrm{R}^{2}\right)$ of 0.85 , as indicated in Fig. $6(\mathrm{~b})$. This confirmed the derived model can be used to accurately predict the bond strength between steel fibers and UHSC matrix. 


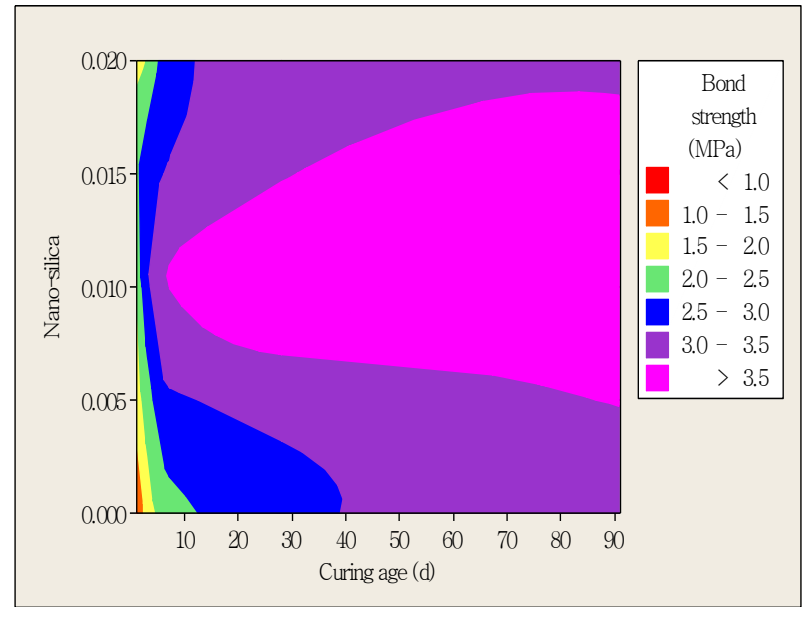

(a) Contour map for bond strength

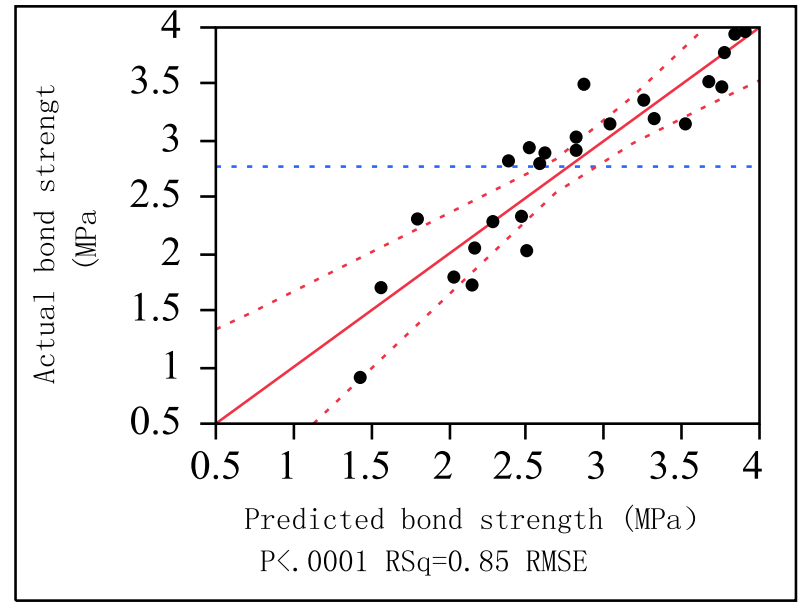

(b) Actual by predicted bond strength

Fig. 6 Simulation of bond strength varied with nano-SiO 2 content and curing age

\subsubsection{Pullout energy}

The effect of different nano- $\mathrm{SiO}_{2}$ contents on pullout energy of fiber-matrix interface are illustrated in Fig. 7. As in the case of bond strength, pullout energy exhibited similar changes with nano-SiO${ }_{2}$ content and curing age. However, the enhancement in pullout energy was far more significant than that of bond strength, especially after $7 \mathrm{~d}$. The pullout energy of the embedded fibers in the matrix made with $1.0 \%$ nano-SiO $\mathrm{S}_{2}$ at 1 d was $73 \mathrm{~N} \cdot \mathrm{mm}$. It increased to 131,119 , and $160 \mathrm{~N} \cdot \mathrm{mm}$ at 7,28 , and $91 \mathrm{~d}$, respectively. The energy dissipation associated with fiber was attributed to adhesion and friction with the surrounding matrix [19, 21]. The adhesion and friction of straight fiber is mainly governed by the quality of C-S-H gel and the density of microstructure at ITZ. The pozzolanic effect of nano- $\mathrm{SiO}_{2}$ with portlandite can lead to greater content of C-S-H gel with good bond, leading to greater bond strength and energy dissipation during fiber pullout process [10, 31]. 


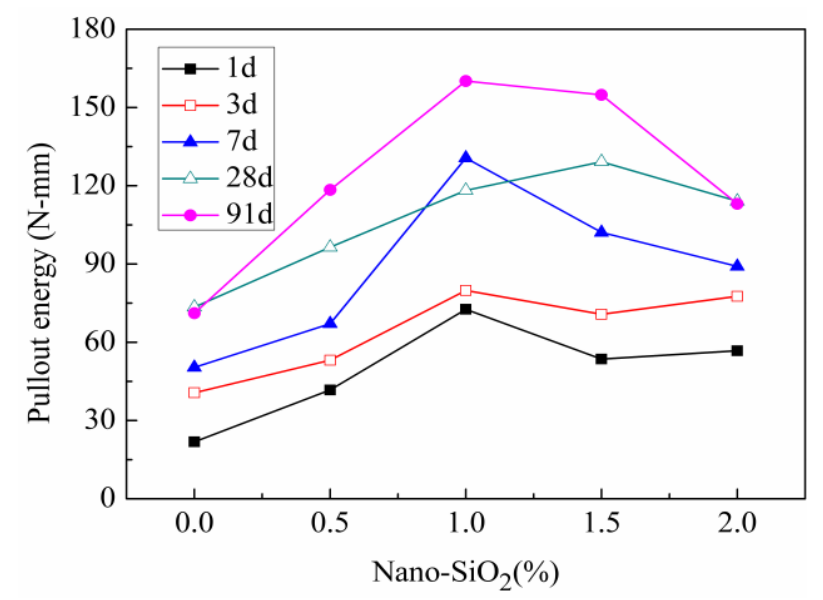

Fig. 7 Effect of nano-SiO 2 content on pullout energy between steel fibers and UHSC matrix

\subsubsection{Pullout energy prediction}

Based on the statistical analysis results as shown in Table 4, the derived model for the pullout energy can be shown as follows:

$$
\mathrm{P}=19.566+2.423 \mathrm{X}_{1}+8868.518 \mathrm{X}_{2}-0.019 \mathrm{X}_{1}^{2}-339417.1 \mathrm{X}_{2}^{2}
$$

where $\mathrm{P}(\mathrm{N} \cdot \mathrm{mm})$ is the predicted pullout energy; $\mathrm{X}_{1}(\mathrm{~d})$ is the curing age; $\mathrm{X}_{2}$ is the nano-SiO${ }_{2}$ content, by mass of cementitious materials.

Table 4 Analysis of variance (ANOVA) for pullout energy

\begin{tabular}{|c|c|c|c|c|}
\hline Term & Estimate & Std Error & t Ratio & Prob $>|t|$ \\
\hline Intercept & 66.133429 & 7.075392 & 9.35 & $<0.0001 *$ \\
\hline Nano- $\mathrm{SiO}_{2}$ content & 2080.176 & 446.2988 & 4.66 & $0.0002 *$ \\
\hline Age & 1.4519914 & 0.227076 & 6.39 & $<0.0001 *$ \\
\hline$\left(\mathrm{Nano}-\mathrm{SiO}_{2}\right.$ content -0.01$) \times\left(\mathrm{Nano}-\mathrm{SiO}_{2}\right.$ content -0.01$)$ & -339417.1 & 75438.27 & -4.50 & $0.0002 *$ \\
\hline$($ Age -26$) \times($ Age -26$)$ & -0.018677 & 0.004957 & -3.77 & $0.0013 *$ \\
\hline$\left(\right.$ Nano- $\mathrm{SiO}_{2}$ content -0.01$) \times($ Age -26$)$ & 6.1018593 & 13.16751 & 0.46 & 0.6483 \\
\hline
\end{tabular}

Note: * denotes statistically significant term

Figure 8 shows the contour map and actual by predicted plot for pullout energy. Samples with nano- $\mathrm{SiO}_{2}$ content in the range from $0.5 \%$ to $1.5 \%$ at later ages exhibited satisfying pullout energy. Its pullout energy after $85 \mathrm{~d}$ was higher than $160 \mathrm{~N} \cdot \mathrm{mm}$. The actual pullout energy fitted well with the predicted values with a correlation coefficient of 0.85 , as shown in Fig. 8(b). 


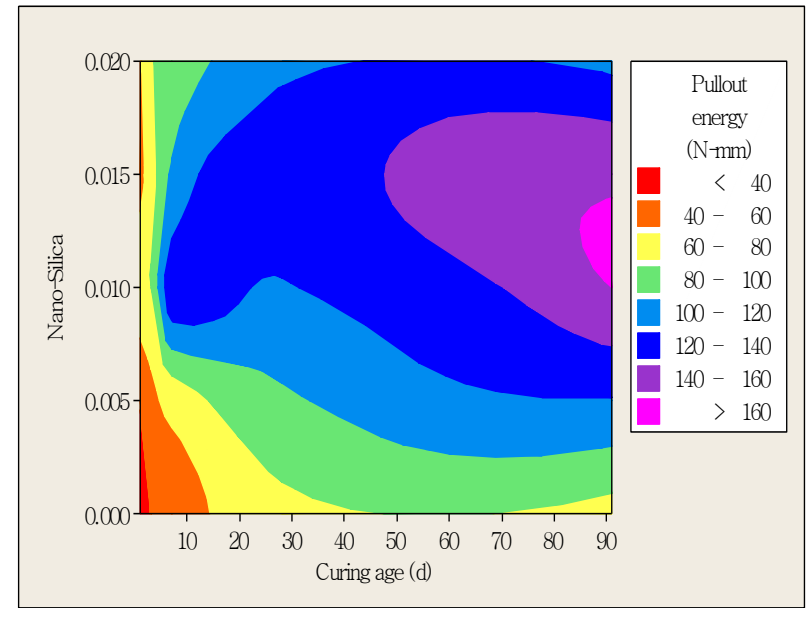

(a) Contour map for pullout energy

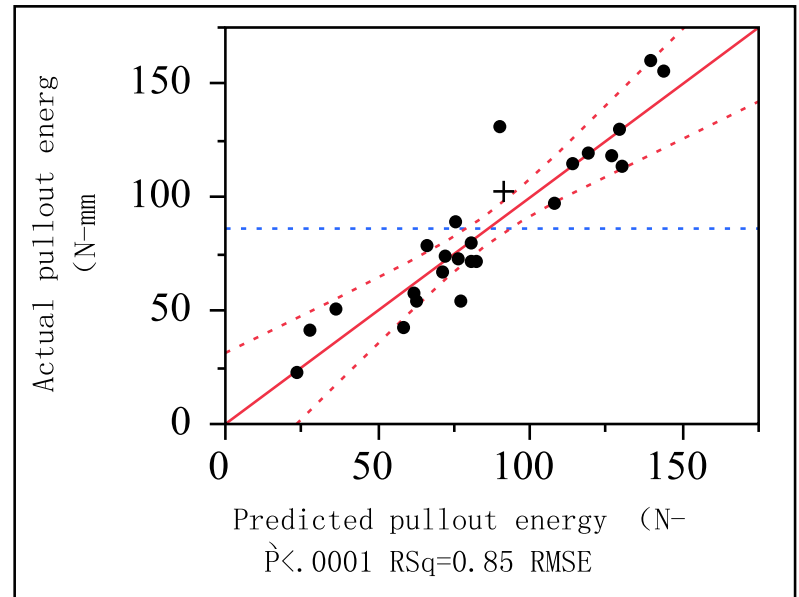

(b) Actual by predicted pullout energy

Fig. 8 Simulation of pullout energy varied with nano- $\mathrm{SiO}_{2}$ content and curing age

\subsection{Microstructural analysis}

\subsubsection{MIP}

Figure 9 illustrates the effect of nano-SiO 2 and curing age on total porosity of UHSC matrix. As can be seen from Fig. 9(a), the porosity of matrix at $1 \mathrm{~d}$ decreased with the nano-SiO $\mathrm{S}_{2}$ content increasing to $1 \%$ but then increased when more nano- $\mathrm{SiO}_{2}$ was used. This is in good agreement with the bond properties. Due to filling and nucleation effects of nano-SiO 2 , the pore structure of UHSC matrix can be refined. However, increased viscosity and agglomeration issues associated with more addition of nano-SiO 2 could introduce air bubbles, thus leading to increased porosity $[9,14]$. This is consistent with the findings reported by others $[9$, $13,15]$. The optimal nano- $\mathrm{SiO}_{2}$ content can depend on many factors, such as $\mathrm{W} / \mathrm{CM}$, mixture proportion, chemical admixture, and nano-particle type [34]. Therefore, the optimal nano- $\mathrm{SiO}_{2}$ content in this research was $1 \%$ by mass of cementitious materials.

Curing age exerted a limited effect on the porosity of NS1.0, as illustrated in Fig. 9(b). The porosity of the NS1.0 matrix at $1 \mathrm{~d}$ was $13 \%$, it slightly decreased to $12.5 \%$ at 7 and $28 \mathrm{~d}$. Because of high surface energy originated from fine nano- $\mathrm{SiO}_{2}$ particles, chemical effect can be rapidly released at very early age. The addition of $1 \%$ nano- $\mathrm{SiO}_{2}$ could decrease the porosity by $29 \%$ and $19 \%$ compared to the reference 
sample at 1 and $28 \mathrm{~d}$, respectively. Rong et al. [9] reported that the porosity of ultra-high performance cementitious composites with $3 \%$ nano- $\mathrm{SiO}_{2}$ at $28 \mathrm{~d}$ was reduced by $25 \%$.

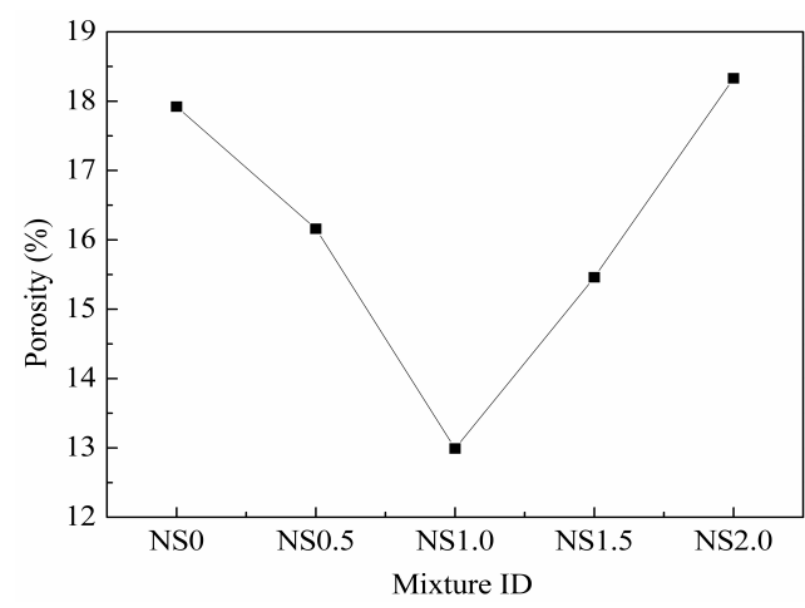

(a) UHSC matrix at $1 \mathrm{~d}$

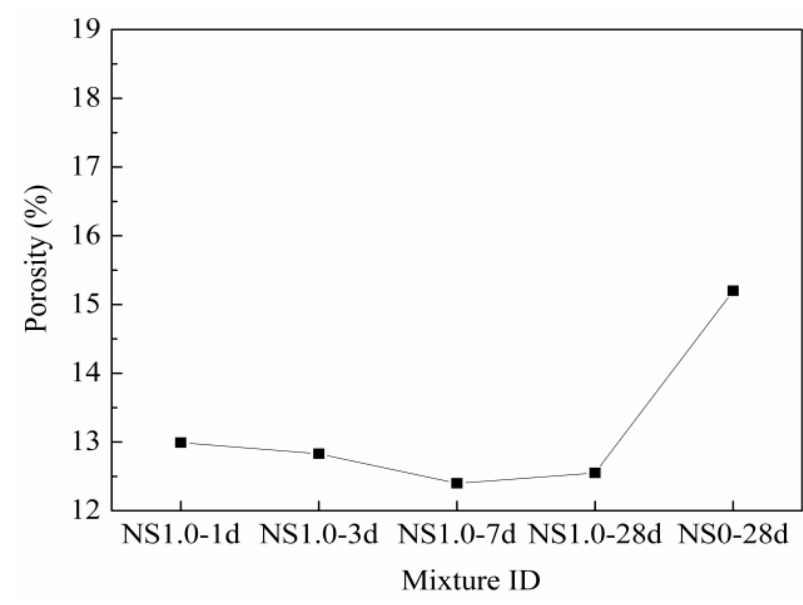

(b) NS1.0 matrix at different ages

Fig. 9 Effect of nano-SiO${ }_{2}$ content and curing age on total porosity of UHSC matrix

Figure 10 shows the pore volume distribution of UHSC matrix, which includes gel micro-pores $(<10$ $\mathrm{nm})$, meso-pores $(10-50 \mathrm{~nm})$, middle capillary pores $(50-100 \mathrm{~nm})$, large capillary pores $(100-5000 \mathrm{~nm})$, and macro-pores $(>5000 \mathrm{~nm})$ [21, 35]. As shown in Fig. 9(a), there were equivalent pore volumes of $25 \%$ for meso-pore, middle capillary pore, large capillary pore, and macro-pore in the reference mixture (NC0) at $1 \mathrm{~d}$. The incorporation of nano- $\mathrm{SiO}_{2}$ particles resulted in refinement of the microstructure with increased volume of meso-pores $(10-50 \mathrm{~nm})$ by $70 \%$. Besides, the nano- $\mathrm{SiO}_{2}$ particles confined the volume of the $50-5000 \mathrm{~nm}$ pores to a limited value of $7 \%$ to $13 \%$.

From Fig. 10(b), it can be seen that the volume of 10-50 $\mathrm{nm}$ pores decreased with age due to further hydration, while the gel micro-pores with diameter less than $10 \mathrm{~nm}$ increased. The volume of meso-pores at $1 \mathrm{~d}$ was $65 \%$, it decreased to $10 \%$ at $28 \mathrm{~d}$. It was reported that the gel micro-pores correspond typically to gel pores in the C-S-H with water held by hydrogen bond [36]. This suggests that nano-SiO${ }_{2}$ can make the microstructure of UHSC denser and render it more homogeneous given the extremely fine particle size of the nano- $\mathrm{SiO}_{2}$ and formation of $\mathrm{C}-\mathrm{S}-\mathrm{H}$ associated with pozzolanic effect. Moreover, the volume of 50-5000 
nm pore was confined to a very small volume, which was $3 \%$ to $7 \%$ only.

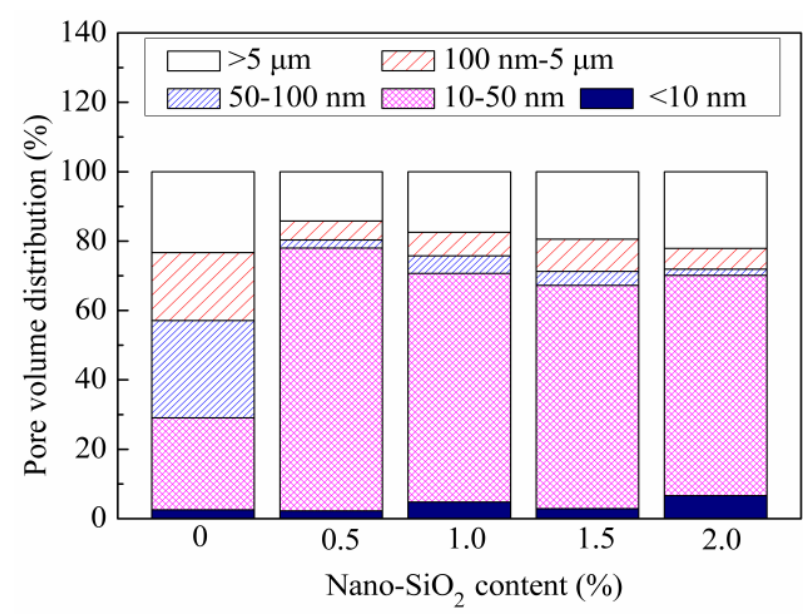

(a) UHSC matrix at $1 \mathrm{~d}$

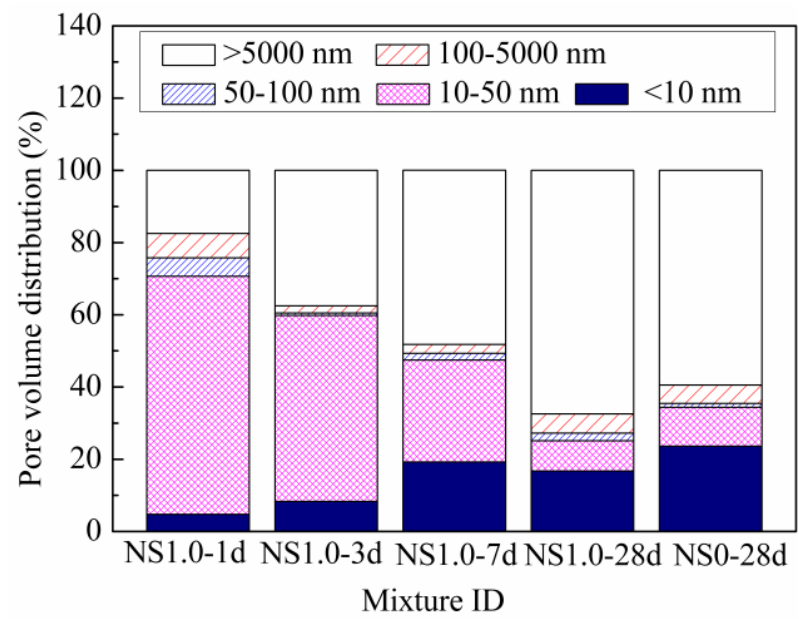

(b) UHSC matrix at different ages

Fig. 10 Pore volume distribution of UHSC matrix made with different nano- $\mathrm{SiO}_{2}$ contents and at various ages

\subsubsection{BSEM image analysis}

BSEM images of an embedded fiber in different UHSC matrices are shown in Fig. 11. BSEM images can indicate different grey levels of unhydrated cement and hydration products, which vary with the atomic numbers. The unhydrated grains appear brighter than hydration products, and pores appear darker [37, 38]. As observed from Fig. 11, the unhydrated cement particles in the UHSC matrix decreased with curing time. There were a lot of unhydrated cement particles in the NS1.0 sample, especially at $1 \mathrm{~d}$. The microstructure around the embedded fiber within the distance of $50 \mu \mathrm{m}$ from the fiber surface was more porous than that in the NS1.0 matrix at $7 \mathrm{~d}$. The porous zone around the fiber at $7 \mathrm{~d}$ might due to bleeding and/or wall effect, which can reduce the contact area with matrix, and thus the bond properties [39].

No obvious ITZ was observed around the fiber in both the NS1.0 and the NS0 matrices at $28 \mathrm{~d}$. However, more porous zone was observed in the NS0 sample (Fig. 11 d), while denser and more homogeneous matrix exhibited in the NS1.0 sample. There were micro-cracks propagating from the fiber edge into the NSO matrix. This may be formed during sample preparation. Micro-hardness testing was conducted on the same sample in the vicinity of fiber (within $240 \mu \mathrm{m}$ to the edge of the fiber) to validate the 
homogeneity of the stiffness of hydration products, as shown in Fig. 1. These results are discussed in Section 3.2.4.

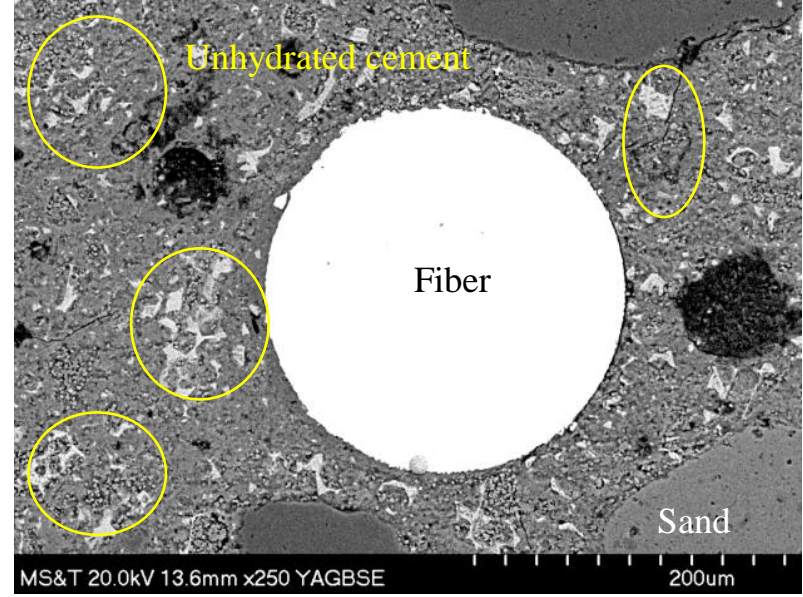

(a) NS1.0 at $1 \mathrm{~d}$

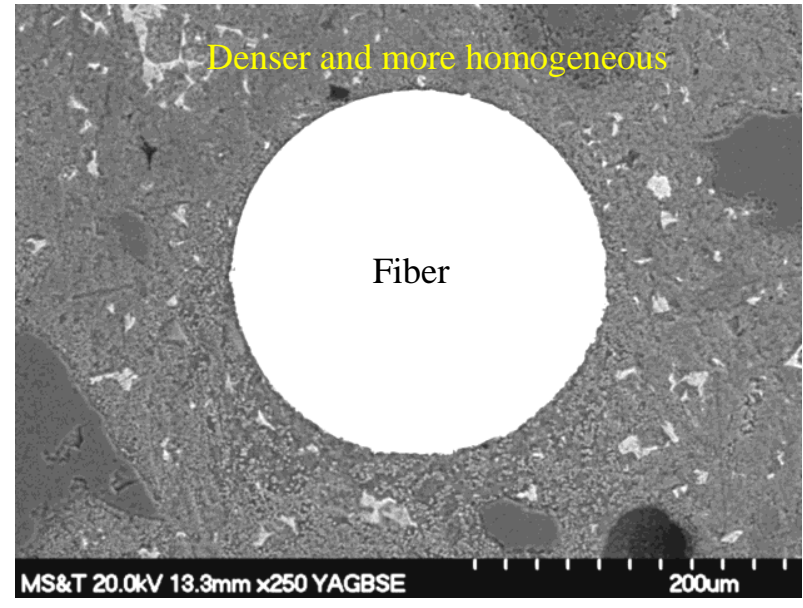

(c) NS1.0 at $28 \mathrm{~d}$

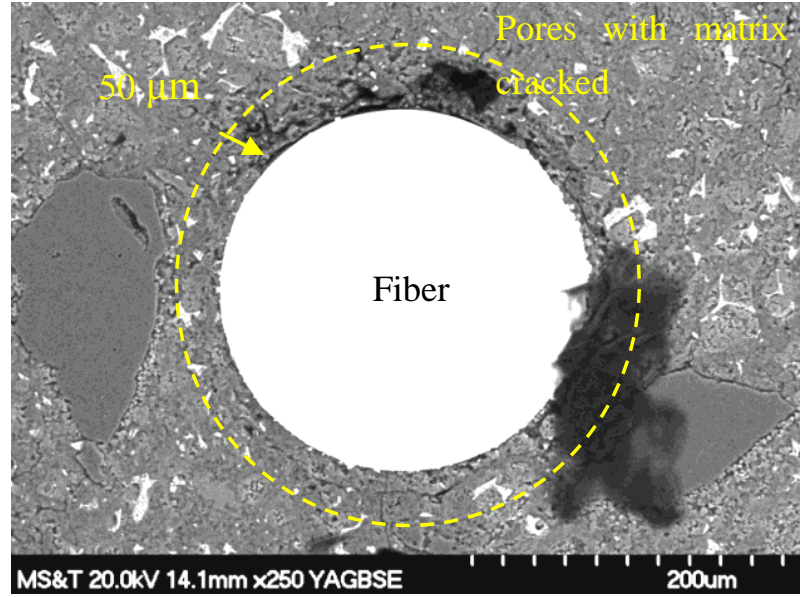

(b) NS1.0 at $7 \mathrm{~d}$

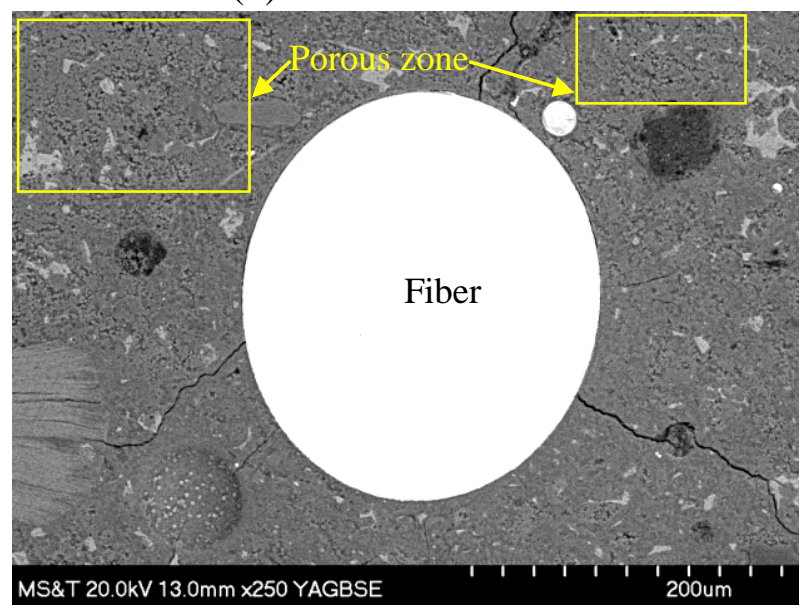

(d) NS0 at $28 \mathrm{~d}$

Fig. 11 BSEM images of UHSC made with 0 and $1 \%$ nano-SiO ${ }_{2}$ with an embedded fiber

Surface plots of BSEM images are illustrated in Fig. 12. These plots reflect the roughness quality of the polished samples shown in Fig. 12. Difference in roughness between fiber and UHSC matrix of approximately $200 \mu \mathrm{m}$ was observed due to very high stiffness of the fiber compared to that of the matrix as discussed in Table 5. 


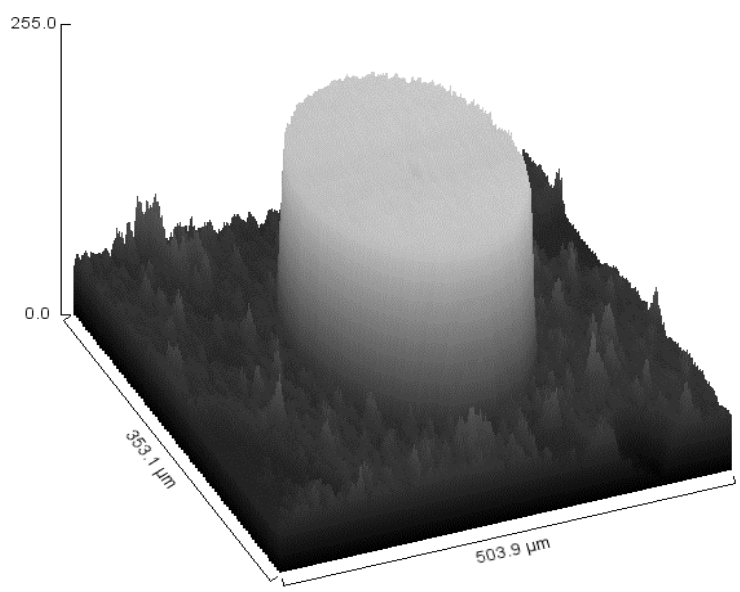

(a) NS1.0 at $28 \mathrm{~d}$

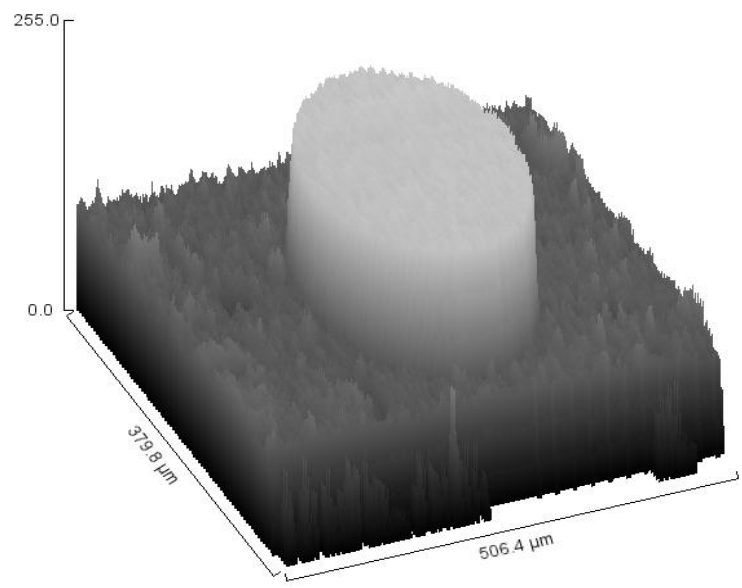

(d) NS0 at $28 \mathrm{~d}$

Fig. 12 Surface plot of UHSC sample with an embedded fiber

\subsubsection{Micro-hardness of the matrix around fiber}

Table 5 summarizes the micro-hardness results of the UHSC samples that were obtained at different distances from the fiber edge. The measurements were conducted on the same sample used for BSEM observation. The micro-hardness of fiber was 770-790 HV. With increase of distance from the fiber edge, the micro-hardness value of the matrix increased. For example, in the NS1.0 sample at $28 \mathrm{~d}$, the micro-hardness of matrix at $40 \mu \mathrm{m}$ from the surface was $84.1 \mathrm{HV}$. It increased to 88.6 and $100.5 \mathrm{HV}$ at 80 and $120 \mu \mathrm{m}$, respectively. The micro-hardness did not significantly change beyond $120 \mu \mathrm{m}$. For the NS1.0 samples at 1 and $7 \mathrm{~d}$, the micro-hardness within distance of $80 \mu \mathrm{m}$ from the fiber edge was obviously lower than that with far distance. This was attributed to the porous microstructure as observed in Fig. 11(a and b).

The micro-hardness increased with prolongation of hydration time. For the NS1.0 sample at 1, 7, and $28 \mathrm{~d}$, the micro-hardness at $80 \mu \mathrm{m}$ from the fiber edge were 82.9, 85.4, and $96.6 \mathrm{HV}$, respectively. In addition, the NS1.0 at $28 \mathrm{~d}$ showed greater micro-hardness compared to the reference sample NS0. This indicated that the incorporation of $1 \%$ nano- $\mathrm{SiO}_{2}$ can enhance the quality of the matrix. It was suggested that bond between fibers and matrix was mainly dominated by adhesion or chemical bond, which is governed by the main hydration product $\mathrm{C}-\mathrm{S}-\mathrm{H}$ with diameter of $10 \mathrm{~nm}$ [40]. In addition to the pozzolanic reaction of 
nano- $\mathrm{SiO}_{2}$ that resulted in greater volume of $\mathrm{C}-\mathrm{S}-\mathrm{H}$ gel, the nano- $\mathrm{SiO}_{2}$ acts as nucleus for the precipitation of C-S-H. These mechanisms can lead to better bond of the C-S-H, and thus enhancing bond properties with steel fiber and matrix $[6,7,9,10]$.

\begin{tabular}{lllll}
\multicolumn{3}{l}{ Table 5 Micro-harness of UHSC matrix within $240 \mu \mathrm{m}$ from the fiber edge } \\
\cline { 2 - 5 } No. & \multicolumn{4}{c}{ Micro-hardness (HV) } \\
\cline { 2 - 5 } & NS1.0-1d & NS1.0-7d & NS1.0-28d & NS0-28d \\
\hline Fiber & 785.5 & 774.6 & 774.6 & 791.0 \\
$40 \mu \mathrm{m}$ & 62.2 & 66.6 & 84.1 & 79.3 \\
$80 \mu \mathrm{m}$ & 82.9 & 85.4 & 96.6 & 84.4 \\
$120 \mu \mathrm{m}$ & 85.4 & 87.9 & 100.5 & 95.2 \\
$160 \mu \mathrm{m}$ & 91.7 & 97.5 & 121.3 & 110.8 \\
$200 \mu \mathrm{m}$ & 95.3 & 98.7 & 123.5 & 105.4 \\
$240 \mu \mathrm{m}$ & 92.0 & 101.0 & 117.2 & 113.5 \\
\hline
\end{tabular}

\subsubsection{XRD analyses}

Figure 13 shows the XRD patterns of the UHSC mixture made with different nano- $\mathrm{SiO}_{2}$ contents and at different ages. The crystal phases of UHSC samples were shown to be composed of quartz $\left(\mathrm{SiO}_{2}\right)$ from sand with characteristic peaks at $2 \theta$ of $21.1^{\circ}, 26.8^{\circ}, 39.7^{\circ}, 50.4^{\circ}$, and $60.1^{\circ}$. Small amounts of $\mathrm{AFt}\left(\right.$ at $9.7^{\circ}$ ), $\mathrm{Ca}(\mathrm{OH})_{2}\left(\right.$ at $18.1^{\circ}, 34.0^{\circ}$, and $47.2^{\circ}$ ), and unhydrated cement clinker, such as $\mathrm{C}_{3} \mathrm{~S}$ and $\mathrm{C}_{2} \mathrm{~S}\left(\right.$ at $29.4^{\circ}, 30.1^{\circ}$, $32.2^{\circ}, 32.8^{\circ}, 34.5^{\circ}$, and $39.0^{\circ}$ ) were also observed. Intensity of $\mathrm{AFt}$ was low given its limited content compared to other phases.

As also illustrated in Fig. 13(a), the NS1.0 and NS2.0 matrix at $28 \mathrm{~d}$ showed a sharper and stronger peak at $28.2^{\circ}$ when compared to the reference sample NS0. This peak also appeared in the NS1.0 mixture at 7, while it was not observed at $1 \mathrm{~d}$. A tobermorite peak was observed at this point [41-43]. This peak might be due to poor-crystalized C-S-H associated with the pozzolanic reaction between nano-SiO 2 and portlandite. According to the literature $[7,33,44]$, the incorporation of nano-silica can convert $1.4 \mathrm{~nm}$ tobermorite into $1.1 \mathrm{~nm}$ tobermorite of $\mathrm{C}-\mathrm{S}-\mathrm{H}$, which favors the compressive and bond strengths. 


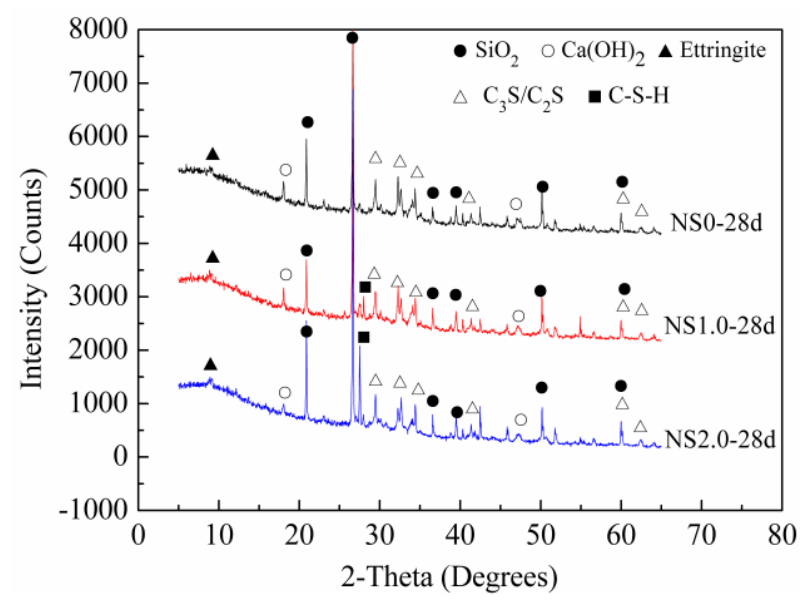

(a) UHSC at different nano-SiO 2 contents

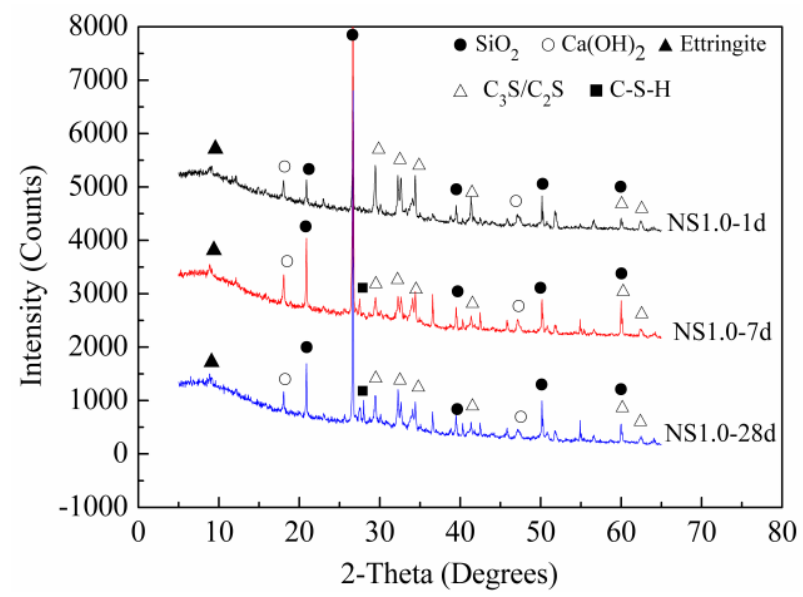

(b) UHSC at different ages

Fig. 13 XRD patterns for UHSC with and without nano- $\mathrm{SiO}_{2}$ at different curing ages

Semi-quantitative analysis of hydration products in the five mixtures presented in Fig. 13 is summarized in Table 6. With the increase of curing time from 1 to $28 \mathrm{~d}$ and nano- $\mathrm{SiO}_{2}$ content from 0 to $2 \%$, the contents of unhydrated cement, $\mathrm{C}_{3} \mathrm{~S}$ and/or $\mathrm{C}_{2} \mathrm{~S}$, and $\mathrm{CH}$ were shown to gradually decrease. A reduction of calcium silicate $\left(\mathrm{C}_{3} \mathrm{~S}\right.$ and/or $\left.\mathrm{C}_{2} \mathrm{~S}\right)$ of $30 \%$ in the NS1.0 sample was observed between 1 and $7 \mathrm{~d}$, then $8 \%$ between 7 and $28 \mathrm{~d}$. This corresponded well with the age-dependency of strength development of matrix, which was enhanced greater from 1 to $7 \mathrm{~d}$ than that from 7 to $28 \mathrm{~d}$. The $\mathrm{CH}$ content of the mixtures with $1 \%$ and $2 \%$ nano- $\mathrm{SiO}_{2}$ at $28 \mathrm{~d}$ was around $4 \%$, which decreased by $33 \%$ compared to that of the reference specimen. This corresponds well with the results from thermal gravimetry analysis, which was $2.4 \%$ [10]. Therefore, nano-SiO 2 acts as nuclei to accelerate the hydration of cement and promotes the assumption of $\mathrm{CH}$ to form more and higher strength $\mathrm{C}-\mathrm{S}-\mathrm{H}$.

Table 6 Semi-quantitative analysis of hydration products based on the XRD analysis

\begin{tabular}{l|l|l|l}
\hline No. & Unhydrated $\mathrm{C}_{3} \mathrm{~S}$ and/or $\mathrm{C}_{2} \mathrm{~S}(\%)$ & $\mathrm{CH}(\%)$ & Ettringite (\%) \\
\hline NS0 - 28 d & 24.0 & 6.0 & 7.1 \\
\hline NS1.0 - 1 d & 34.3 & 7.1 & 8.1 \\
\hline NS1.0 - 7 d & 24.0 & 5.3 & 7.1 \\
\hline NS1.0 - 28 d & 22.0 & 4.5 & 6.8 \\
\hline NS2 .0 - 28 d & 21.0 & 4.0 & 6.0 \\
\hline
\end{tabular}




\section{Conclusions}

This study focused on the development of microstructure and fiber-matrix bond properties in UHSC with different nano- $\mathrm{SiO}_{2}$ contents varying from 0 to $2 \%$, by the mass of cementitious materials. Characterization techniques, including MIP, BSEM, micro-hardness, and XRD, were adopted to investigate the change in quality of matrix and fiber-matrix interface. A statistical model related to either bond strength or pullout energy to curing time and nano- $\mathrm{SiO}_{2}$ content was established. Based on the results from this study, the following conclusions can be drawn:

(1) $\mathrm{Nano}-\mathrm{SiO}_{2}$ can significantly enhance the interfacial bond properties between fibers and UHSC matrix. The bond strength and pullout energy increased first with the increase of nano-SiO 2 content, but then decreased when a critical value of $1 \%$ was exceeded. Such change was consistent with the compressive strength development of matrix. The bond strength and pullout energy of UHSC with $1 \%$ nano-SiO 2 after 28-d standard curing were enhanced by approximately $35 \%$ and $70 \%$, respectively, when compared to the reference sample.

(2) The proposed quadratic model based on the response surface methodology can efficiently predict the bond strength and pullout energy correlating with curing time and nano- $\mathrm{SiO}_{2}$ content. The curing age and nano- $\mathrm{SiO}_{2}$ content had an individually significant influence on the bond properties, but no interaction effect exhibited between the two factors.

(3) According to the microstructural analysis, the addition of $1 \%$ nano- $\mathrm{SiO}_{2}$ resulted in the lowest porosity of matrix associated with denser and more homogeneous microstructure. ITZ with a thickness of 50 $\mu \mathrm{m}$ was observed due to wall and bleeding effect in correlation with lower micro-harness compared to the bulk matrix. The addition of $1 \%$ nano- $\mathrm{SiO}_{2}$ improved the chemical bond of $\mathrm{C}-\mathrm{S}-\mathrm{H}$ to fiber at later age as confirmed by an appearance of a sharper and stronger new peak of tobermorite from XRD analysis and greater micro-hardness. 


\section{Acknowledgements}

The authors would like to acknowledge financial support of the National Science Foundation of China (Nos. U1305243 and 51378196) and Energy Consortium Research Center (No. SMR-1406-09) as well as the RE-CAST University Transportation Center (No. DTRT13-G-UTC45) at Missouri University of Science and Technology. The authors are grateful to Lei Yan and Jingwei Zhang for providing valuable suggestions on sample preparation for BSEM.

\section{References}

[1] J.J. Buck, D.L. McDowell, M. Zhou. Effect of microstructure on load-carrying and energy-dissipation capacities of UHPC. Cem Concr Res, 2013; 43: 34-50.

[2] R.F. Zollo. Fiber-reinforced concrete: an overview after 30 years of development. Cem Concr Compos, 1997; 19(2): 107-122.

[3] Z. Wu, C. Shi, W. He. Comparative study on flexural properties of ultra-high performance concrete with supplementary cementitious materials under different curing regimes. Constr Build Mater, 2017; 136: 307-313.

[4] X.H. Wang, S. J.Y. Jacobsen, He, Z.L. Zhang, S.F. Lee, H.L. Lein. Application of nanoindentation testing to study of the interfacial transition zone in steel fiber reinforced mortar. Cem Concr Res, 2009; 39(8), 701-715.

[5] Z. Wu, C. Shi, W. He, D. Wang. Uniaxial compression behavior of ultra-high performance concrete with hybrid steel Fiber. Journal of Materials in Civil Engineering, 2006; 28(12): 06016017.

[6] Z. Wu, C. Shi, W. He, L. Wu. Effects of steel fiber content and shape on mechanical properties of ultra high performance concrete. Constr Build Mater, 2016; 103: 8-14. 
[7] P. Richard, M. Cheyrezy. Composition of reactive powder concretes. Cem Concr Res, 1995; 25(7): 1501-1511.

[8] C. Shi, Z. Wu, J. Xiao, D. Wang, Z. Huang, F. Zhi. A review on ultra high performance concrete Part I: raw materials and mixture design. Constr Build Mater, 2015; 101: 741-751.

[9] Z.D. Rong, W. Sun, H.J. Xiao, G. Jiang. Effects of nano-SiO${ }_{2}$ particles on the mechanical and microstructural properties of ultra-high performance cementitious composites. Cem Concr Compos, 2015; 56: $25-31$.

[10] Z. Wu, C. Shi, K.H. Khayat, S. Wan. Effects of different nanomaterials on hardening and performance of ultra-high strength concrete (UHSC). Cem Concr Compos, 2016; 70: 24-34.

[11] B.W. Jo, C.H. Kim, G.H. Tae, J.B. Park. Characteristics of cement mortar with nano-SiO ${ }_{2}$ particles. Constr Build Mater, 2007; 21: 1351-5.

[12] G.Quercia, G. Hüsken, H.J.H. Brouwers. Water demand of amorphous nano silica and its impact on the workability of cement paste. Cem Concr Res, 2012; 42(2): 344-357.

[13] M.H. Beigi, J. Berenjian, O.L. Omran, A.S. Nik, I.M. Nikbin. An experimental survey on combined effects of fibers and nanosilica on the mechanical, rheological, and durability properties of self-compacting concrete. Materials \& Design, 2013; 50: 1019-1029.

[14] S. Kawashima, P.K. Hou, D.J. Corr, S.P. Shah. Modification of cement-based materials with nanoparticles. Cem Concr Compos, 2013; 36: 8-15.

[15] P.K. Hou, S. Kawashima, K.J. Wang, Wang, D.J. Corr, J.S Qian, S.P. Shah. Effects of colloidal nanosilica on rheological and mechanical properties of fly ash-cement mortar. Cem Concr Compos, 2013; 35(1): 12-22.

[16] A. Nazari, S. Riahi. The effects of $\mathrm{SiO}_{2}$ nanoparticles on physical and mechanical properties of high strength compacting concrete. Compos B, 2011; 42: 570-578. 
[17] M. Sonebi, E. García-Taengua, K.M.A. Hossain, J. Khatib, M. Lachemi. Effect of nanosilica addition on the fresh properties and shrinkage of mortars with fly ash and superplasticizer. Constr Build Mater, 2015; 84: 269-276.

[18] D. Adak, M. Sarkar, S. Mandal. Effect of nano-silica on strength and durability of fly ash based geopolymer mortar. Constr Build Mater, 2014; 70: 453-459.

[19] D.Y. Kong, X.F. Du, S. Wei, H. Zhang, Y. Yang, S.P. Shah. Influence of nano-silica agglomeration on microstructure and properties of the hardened cement-based materials. Constr Build Mater, 2012, 37: 707-715.

[20] C. Shi, D. Wang, L. Wu, Z. Wu. The hydration and microstructure of ultra high-strength concrete with cement-silica fume-slag binder. Cem Concr Compos, 2016; 61: 44-52.

[21] Z. Wu, C. Shi, K.H. Khayat. Influence of silica fume content on microstructure development and bond to steel fiber in ultra-high strength cement-based materials (UHSC). Cem Concr Compos, 2016; 71: 97-109.

[22] Chinese National Standard. The test method for property of bond between steel fiber and motar. CECS13-2009. 64-68, Beijing, China, 2009.

[23] A.E. Naaman, G.G. Namur, J.M. Alwan, H.S. Najm. Fiber pullout and bond slip I: analytical study. J Struct Eng 1991; 117(9): 2769-2790.

[24] A.E. Naaman, G.G. Namur, J.M. Alwan, H.S. Najm. Fiber pullout and bond slip II: experimental validation. J Struct Eng 1991; 117(9): 2791-2800.

[25] V.M.C.F. Cunha, J.A. Barros, J.M. Sena-Cruz. Pullout behaviour of hooked-end steel fibres in self-compacting concrete. Civil Engineering, 2017, Report.

[26] K. Wille, A.E. Naaman. Effect of ultra-high-performance concrete on pullout behavior of high-strength brass-coated straight steel fibers, ACI Mater. J. 2013; 110 (4): 451-461.

[27] J.M. Alwan, A.E. Naaman, W. Hansen. Pull-out work of steel fibers from cementitious composites: 
analytical investigation. Cem Concr Compos, 1991; 13(4): 247-255.

[28] P. Bartos. Analysis of pullout tests on fibers embedded in brittle matrices. Journal of Materials Science. 1980; 15(12): 3122-3128.

[29] Y.W. Chan, S.H. Chu. Effect of silica fume on steel fiber bond characteristics in reactive powder concrete. Cem Concr Res, 2004; 34: 1167-1172.

[30] S. Masse, H. Zanni, J. Lecourtier, J.C. Roussel, A. Rivereau. ${ }^{29}$ Si solid state NMR study of tricalcium silicate and cement hydration at high temperature, Cem Concr Res, 1994; 23(5): 1169-1177.

[31] Z. Wu, C. Shi, K.H. Khayat, D. Zhu. Optimization of microstructure and pullout behavior of fibers in ultra-high strength concrete with the help of nano-particles and heat curing. In proceeding 1st International Conference on UHPC Materials and Structures 27 - 30 Oct 2016, Changsha, China.

[32] T. Abu-Lebdeh, S. Hamoush, W. Heard, B. Zornig. Effect of matrix strength on pullout behavior of steel fiber reinforced very-high strength concrete composites. Constr Build Mater, 2011; 25(1): 39-46.

[33] E.K. Nambiar, K. Ramamurthy. Models relating mixture composition to the density and strength of foam concrete using response surface methodology. Cem Concr Compos, 28(9): 752-760.

[34] F. Sanchez, Sobolev K. Nanotechnology in concrete-a review. Constr Build Mater, 2010, 24(11): 2060-2071.

[35] Q. Zeng, K. Li, T. Chong, P. Dangla. Pore structure characterization of cement pastes blended with high-volume fly-ash. Cem Concr Res, 2012; 42(1): 194-204.

[36] H.M. Jennings. A model for the microstructure of calcium silicate hydrates in cement paste. Cem Concr Res, 2000; 30: 101-116.

[37] K.L. Scrivener. Backscattered electron imaging of cementitious microstructures: understanding and quantification. Cem Concr Compos, 2004, 26: 935-945.

[38] J.E. Ash, M.G. Hall, J.I. Langford, M. Mellas. Estimations of degree of hydration of Portland cement 
pastes Cem Concr Res, 1993; 23(2): 399-406.

[39] K.L. Scrivener, A.K. Crumbie, P. Laugesen. The interfacial transition zone (ITZ) between cement paste and aggregate in concrete. Interface Science 2004; 12(4): 411-421.

[40] A. Pompo, P.R. Stupak, L. Nicolais. B. Marchese. Analysis of steel fiber pull-out from a cement matrix using video photography. Cem Concr Compos, 1996; 18(1): 3-8.

[41] S. Wang, X. Peng, L. Tang, L. Zeng, C. Lan. Influence of inorganic admixtures on the 11 A-tobermorite formation prepared from steel slags: XRD and FTIR analysis. Constr Build Mater, 2014, 60: 42-47.

[42] A. Nonat. The structure and stoichiometry of CSH. Cem Concr Res, 2004, 34(9): 1521-1528.

[43] M. Aly. S.J. Hashmi, A.G. Olabi, M. Messeiry, E.F. Abadir, A.I. Hussain. Effect of colloidal nano-silica on the mechanical and physical behaviour of waste-glass cement mortar. Materials \& Design 2012, 3: 127-135.

[44] W. Watcharapong, P. Thongsanitgarn, P. Chindaprasirt, A. Chaipanich. Thermogravimetry of ternary cement blends, J. Therm. Anal. Calorim. 2013; 113(3): 1079-1090. 